\title{
ENTREVISTA COM A PROFESSORA ITALA MARIA LOFFREDO D'OTTAVIANO: UMA INTRODUÇÃO À LÓGICA, ÀS LÓGICAS NÃO CLÁSSICAS E À TEORIA DE SISTEMAS
}

Itala Maria Loffredo D’Ottaviano

Professora do Departamento de Filosofia da Universidade Estadual de Campinas (Unicamp). Pós-doutorado na Universidade da Califórnia - Berkeley, na Universidade de Stanford e na Universidade de Oxford. Doutora em Matemática pela Universidade Estadual de Campinas. Mestra em Matemática pela Universidade Estadual de Campinas. E-mail:itala@cle.unicamp.br

Apresenta a entrevista da Prof ${ }^{a}$. Dr ${ }^{\mathrm{a}}$. Itala Maria Loffredo D'Ottaviano em sua vinda à Belém do Pará, para ministrar o minicurso de teoria dos sistemas complexos" referente à Disciplina de "UMA INTRODUÇÃO À LÓGICA, ÀS LÓGICAS NÃO CLÁSSICAS E À TEORIA DE SISTEMAS”, realizada no período de 07 a 11 de Novembro de 2016. A entrevista apresenta questões dadas aos participantes do minicurso, sobretudo, do Grupo de Filosofia Temática referente as relações e indagações sobre à Lógica Paraconsistente.

Sam Alves - O princípio da não - contradição, ainda pode ser considerado como um princípio válido epistemologicamente? Se sim, em quais situações ele poderia ser válido?

I. M. L. D’Ottaviano - Desde a criação, a partir do início do século $\mathrm{XX}$, das contemporaneamente chamadas lógicas não clássicas, sabemos que pode existir uma pluralidade de lógicas. Lógicas distintas podem ser adequadas, válidas, para domínios distintos do conhecimento.

Nas lógicas não clássicas, as leis básicas do pensamento Aristotélico podem não ser válidas, em geral: nas lógicas não reflexivas não vale, em geral, o Princípio da (Reflexividade) da Identidade; nas lógicas paracompletas não vale o Princípio do Terceiro Excluído; e nas lógicas paraconsistentes não vale, em geral, o Princípio da (Não) Contradição. 
Uma teoria é consistente se não existe uma fórmula $A$ de sua linguagem tal que $A$ e a negação de $A$ sejam teoremas; caso contrário, a teoria é inconsistente. Uma teoria é trivial se toda fórmula de sua linguagem é teorema.

Uma lógica é dita paraconsistente se pode ser usada como lógica subjacente para teorias inconsistentes e não triviais, que são chamadas teorias paraconsistentes.

Em toda lógica paraconsistente, de uma fórmula $A$ e sua negação $\neg A$ não é possível, em geral, deduzir qualquer fórmula $B$. Ou seja, nas lógicas paraconsistentes não é válido o ex falso sequitur quodlibet, hoje também conhecido como Princípio da Explosão.

A lógica clássica, no seu estado atual, é poderosa e encerra toda a velha silogística aristotélica, convenientemente reformulada. Toda teoria dedutiva baseada na lógica clássica como, por exemplo, a matemática tradicional - é inconsistente se, e somente se, é trivial. Ou seja, em toda teoria cuja lógica subjacente é a lógica clássica, é válido o Princípio da Explosão.

Nesse sentido, o Princípio da (Não) Contradição permanece válido em todas as teorias cuja lógica subjacente é a lógica clássica Aristotélica. Isso também ocorre com teorias baseadas em outros tipos de lógicas não clássicas, como por exemplo as lógicas modais, as lógicas intuicionistas e as lógicas polivalentes.

Como é bem sabido, Aristóteles, no Livro $\Gamma$ de sua Metafísica, defende o Princípio da Não Contradição - para ele, sem o Princípio da Não Contradição o conhecimento é impossível.

Nas lógicas paraconsistentes, entretanto, o Princípio da Não Contradiação não é válido, em geral. Porém, mesmo com o desenvolvimento das lógicas paraconsistentes, e apesar de seu uso em várias áreas, inclusive com aplicações tecnológicas (tais como a ética, lógica doxástica, teoria das probabilidades, fundamentos do cálculo diferencial, inteligência artificial, databases, data mining, engenharia de software, processamento de sinais, computação neural, controle inteligente, robótica, controle de tráfico em grandes cidades, teoria da decisão, teoria de jogos, finanças, semântica formal, linguística computacional e fundamentos da mecânica quântica), permanence a questão - o Princípio da Não Contradição pode ainda ser considerado como um princípio válido epistemologicamente?

Acredito que, independentemente de sua validade, ou não, em teorias específicas, para certas áreas do conhecimento, o Princípio da Não Contradição certamente "não é válido, em geral, no domínio epistemológico. 
Pensemos nessa questão, tomando um exemplo sempre mencionado por da Costa, a geometria: dentre as variadas geometrias, qual é a verdadeira? A resposta depende da posição que se adotar: do prisma matemático puro, não há geometria mais verdadeira do que as demais, todas elas são "matematicamente verdadeiras", como, por exemplo, as geometrias não arquimedianas, as geometrias não euclidianas, a geometria projetiva finita, as não pashianas e as geometrias de Riemann; do ponto de vista aplicado, de forma semelhante, em mecânica quântica comum recorre-se à geometria euclidiana, em teoria quântica de campos, à geometria da relatividade restrita, e em relatividade geral utiliza-se uma ampliação das geometrias de Riemann.

Como outro exemplo, pensemos em teorias físicas. Qual a teoria verdadeira, a mecânica clássica Newtoniana, a teoria da relatividade (estrita, ou geral), ou a mecânica quântica? A resposta seria: depende do prisma que se adote, E deve ser observado, aqui, que essas são teorias físicas eminentemente contraditórias entre si, porém continuam coexistindo, e cada uma delas dá conta de uma grande gama de fenômenos.

Apesar dos matemáticos desenvolverem seu trabalho baseados na suposição de que a matemática é livre de contradições, nas ciências empíricas as contradições parecem inevitáveis e a presença de contradições não é condição suficiente para que se perca o interesse pelas teorias.

Em lógica, parece que a lógica clássica tem papel de relevo; no entanto, já se sugeriu a aplicação de lógicas paraconsistentes em mecânica quântica, da lógica intuicionista de Brouwer-Heyting em cosmologia e da lógica paraconsistente em psicanálise.

Assim sendo, reitero minha resposta à questão apresentada: a validade do Princípio da Não Contradição depende, não apenas da lógica utilizada, mas também da posição epistemologica e dos pressupostos metafísicos adotados.

Sergio Nunes - A história da Lógica que vai de Aristóteles e medievalistas até Frege, contém proximidades metodológicas e de princípios e, ainda ao nível do discurso, a lógica contemporânea da Paraconsistência de da Costa se mantém no campo da linearidade que inclui a contradição que é uma categoria racional. 
Nos Sistemas Complexos, além de abranger essa variável lógica, suplanta no seu raio de ação essa condição de contradição e agrega na sua estrutura, digamos assim, uma zona para além da contradição que se dá nos processos de emergência por exemplo.

Como sair ou superar, se possível for, dessa correlação estrita de uma lógica racionalista, em vista de uma lógica que explicite e decodifique a estrutura da ação de organismos ou elementos, de forma emergenciada como se dá num dado processo, como no processo histórico por exemplo?

I. M. L. D'Ottaviano - Creio que não temos ainda uma resposta para essa questão. Entendo que estaríamos nos perguntando sobre qual seria uma lógica adequada para expressar os processos inerentes a sistemas complexos nos quais ocorrem fenômenos de emergência.

Estaríamos buscando uma lógica que pudesse expressar a regularidade desse tipo de processos dinâmicos complexos e, muitas vezes, criativos.

Tenho me preocupado com isso. Uma lógica, que possa ser considerada como subjacente a processos complexos que comportem emergências, não a temos ainda formalmente proposta. Porém, parece-me, deverá ser, necessariamente, uma lógica não clássica pelo menos paraconsistente - digo pelo menos, pois parece-me que deverá ser também paracompleta.

Luís Eduardo Ramos - De um lado, há sistemas que variam em níveis e graus (princípio gardualista), tal como é o caso dos corpos orgânicos e celestes, e mesmo da própria mente, os quais podem variar determinadas grandezas ou parâmetros em graus infinitos dentro de uma dada escala, como por exemplo a variação em grau das suas temperaturas ou dos seus estados mentais (passagem da vigília ao sonho, e vice versa). De outro, há possibilidade de formalizar o conceito de sistema mediante o conceito de estrutura.

Como seria possível associar o princípio gradualista ao conceito de estrutura? Seria possível elaborar logicamente o conceito de uma estrutura (sistema) que varia em graus? 
I. M. L. D’Ottaviano - Do meu ponto de vista, sistemas são estruturas (coleções de elementos, munidas de relações) com funcionalidade. Os sistemas são caracterizados por sua organização, cujo estado é dado pela medida de parâmetros que variam no tempo.

Os sistemas desenvolvem processos, que podem ser auto-organizados, complexos e criativos. Nesses processos, podem ocorrer variações significativas no sistema, que alteram sua estrututura e sua organização. O grau de complexidade do sistema pode ser alterado, nessa dinâmica sistêmica.

Considero que somente pensando em processos podemos considerar a variação do grau de complexidade de estruturas subjacentes a sistemas.

Angela Lima Gadelha - Já que a lógica é a ciência do pensamento, e tem como papel fundamental o entendimento da lingüística, seria necessário que ela conseguisse formalizar qualquer tipo de argumento. Perante esta asserção, quais seriam os problemas, primordiais entre lógica clássica e não clássica?

I. M. L. D’Ottaviano - Não seria correto dizer que o papel fundamental da lógica consiste no entendimento da linguística.Os sistemas lógicos contemporâneos são construídos a partir de linguagens artificiais, nas quais são expressos os princípios considerados básicos chamados de axiomas.

Os argumentos são desenvolvidos - e formalizados - a partir dos axiomas e regras de dedução da lógica considerada. Qualquer que seja a lógica, ela tem, portanto, suas leis básicas, que são expressas na linguagem formalizada considerada.

Como o conjunto de axiomas da lógicas clássica é distinto do conjunto de axiomas de qualquer lógica não clássica, os argumentos são nelas formalizados de forma distinta.

Nesse sentido, não há qualquer problema formal, sintático ou semântico. 
D’OTTAVIANO, Itala Maria Loffredo. Entrevista com a professora Itala Maria Loffredo D’Ottaviano: uma introdução à lógica, às lógicas não clássicas e à teoria de sistemas. Complexitas - Rev. Fil. Tem., Belém, v. 1, n. 2, p. 3-9, jul./dez. 2016. Disponível em:< http://www.periodicos.ufpa.br/index.php/complexitas/article/view/4354>. Acesso em: 20 abr. 2017. 